\title{
A percepção das mães sobre a volição de crianças com paralisia cerebral para o engajamento em ocupações do cotidíano infantil
}

\author{
Alyne Kalyane Câmara de Oliveira* \\ Maria Luísa Guillaumon Emmel**
}

\section{Resumo}

Volição, como a vontade em se envolver/realizar atividades cotidianas, é considerada pré-requisito do fazer humano. Nas crianças com necessidades especiais, como as com paralisia cerebral (PC) que experimentam déficits no controle sensório-motor e músculo-esquelético, a volição pode atuar como característica influente para o seu engajamento em ocupações. A família é uma importante mediadora no processo volicional infantil, contudo, faltam investigações sobre sua influência na volição de crianças com necessidades especiais. Objetivou-se identificar como as mães percebem e lidam com a volição da criança com PC, para realizar atividades do cotidiano na área escolar, como brincadeiras e o autocuidado. Participaram 6 mães de crianças com PC, entre 6 e 9 anos, níveis I e IV do GMFCS, em uma unidade saúde-escola do interior Paulista, as quais responderam uma entrevista semiestruturada, baseada no The Volitional Questionary. A partir da análise de conteúdo, emergiram 3 eixos temáticos: a) percepção das mães sobre a volição das crianças; b) percepção das mães sobre o seu papel no processo volicional das crianças, e c) estratégias utilizadas pelas mães para incentivar as crianças a desenvolverem a volição. Resultados mostraram que as mães percebem a relação volição da criança versus envolvimento nas atividades, bem como a importância delas na volição infantil voltada a atividades que julgam relevantes, principalmente as escolares formais e do autocuidado, com menor ênfase para as do brincar. Essas mães buscam implementar formas de incentivo, mas revelaram conhecimento limitado sobre estratégias de estimulação da volição, mostrando a necessidade de investimentos de educação em saúde para a orientação desses familiares.

Palavras-chave: Paralisia Cerebral; Volição; Educação Especial.

\footnotetext{
* Doutoranda do Programa de Pós-Graduação em Educação Especial da Universidade Federal de São Carlos (UFSCar), São Carlos, São Paulo, Brasil.

** Professora Doutora do Programa de Pós Graduação em Educação Especial e do Programa de Pós Graduação em Terapia Ocupacional da Universidade Federal de São Carlos (UFSCar), São Carlos, São Paulo, Brasil.
} 


\title{
The perception of mothers about the volition of children with cerebral palsy for the engagement in everyday life occupations
}

\begin{abstract}
Volition, as the willingness to engage/performing daily activities, is considered a prerequisite of human doing. In children with special needs such as cerebral palsy (CP) who deal with deficits of sensorimotor control and musculoskeletal, the volition can work as an influential feature to their engagement in occupations. The family is an important mediator in the child's volitional process. However, researches about influence of the volition of children with special needs are scarce. This study aimed to identify how mothers perceive and deal with the volition of the child with $\mathrm{CP}$ to perform daily activities in scholar, play and self-care areas. Participated six mothers of children with CP, between 6 and 9 years old, levels I and IV of the GMFCS in a school -health unit inside Paulista, who answered a semistructured interview based on The Volitional Questionnaire. Based on the analysis of the content, three topics emerged: a) mother's perceptions about the volition of children; b) mothers' perception regarding their role in the child's volitional process and c) strategies used by mothers to encourage children to develop volition. Results showed that mothers perceive the relationship of the child volition versus involvement in activities and their importance in child's volition for activities who judge relevant, mainly the formal school activities and self-care, with slightest consideration for the play. These mothers are looking for ways to implement the incentive, but they have revealed limited knowledge about strategies for stimulation of volition, showing the need for investments in health education for the guidance of those families.
\end{abstract}

Keywords: Cerebral Palsy; Volition; Special Education.

\section{Introdução}

O desempenho satisfatório dos papéis ocupacionais relacionados à participação e aprendizagem escolar, ao brincar e ao cuidado pessoal são esperados na infância. Contudo, crianças com necessidades especiais, como é o caso da deficiência física, apresentam dificuldades para explorar ambientes e se engajar em atividades típicas. A paralisia cerebral (PC), um grupo de desordens do movimento e postura, atribuídos a distúrbios não-progressivos durante o desenvolvimento do cérebro fetal ou infantil (ROSEMBAUM et al., 2007), com incidência relativamente alta e frequente na população mundial (LEITE; PRADO, 2004; LAMMI; LAW, 2003), faz com que ao experimentarem déficits no controle sensório-motor e músculo-esquelético, crianças, nesta condição, encontrem desafios na aquisição de habilidades funcionais necessárias à participação nas áreas de desempenho ocupacional infantil. 
Focalizando o desempenho ocupacional e as habilidades que as crianças com PC apresentam ao realizar tarefas do cotidiano, hipotetiza-se que a limitação ou ampliação neste desempenho também possa ser influenciada pela vontade da criança em se envolver e realizar tais atividades, uma vez que a volição pode ser entendida como um pré-requisito do fazer humano, de acordo com o Modelo da Ocupação Humana $(\mathrm{MOH})$.

$\mathrm{O} \mathrm{MOH}$ compreende o homem como um sistema aberto, interagindo com o ambiente, continuamente modificando-o e sendo modificado por ele no decorrer de sua vida (REBELLATO, 2012; HAGEDORN, 2003; KIELHOFNER, 2002). A organização interna do sistema aberto é conceituada por três subsistemas interligados - volição, habituação e desempenho - os quais interagem entre si e, o resultado da modulação de suas ações é o comportamento ocupacional (KIELHOFNER, 2009; HAGEDORN, 2003).

O subsistema da volição faz referência aos mecanismos pelos quais escolhemos o que fazer; a força interna da pessoa para tomar iniciativa para a ocupação, ou seja, é o processo pelo qual cada sujeito orienta suas escolhas de atividades. Conforme Kielhofner (2009), este subsistema consiste em pensamentos e sentimentos que ocorrem em um ciclo de: antecipação das possibilidades do fazer; escolha do fazer; experimentação do que se faz; e interpretação da experiência.

Kielhofner (2009) descreve que o subsistema volicional é formado por três componentes: a causação pessoal, que reflete a percepção do indivíduo sobre sua capacidade e eficiência para realizar atividades; os valores, que se referem ao que a pessoa considera importante/significativo fazer e, os interesses pessoais, como a tendência de buscar satisfação, prazer e bem estar em certas situações.

Ressalta-se que o MOH enfatiza o meio ambiente como um espaço de oferta, oportunidades, recursos, demandas e limitações para cada indivíduo (CASTANHARO, 2011), sendo assim, os componentes dosubsistema volicional são influenciados pelo ambiente e contexto em que a pessoa está inserida. Segundo Chern et al. (1996), entender a volição de uma pessoa para o engajamento em ocupações requer apreciação simultânea dos componentes descritos e da influência do ambiente.

Ao lidar com crianças, relembra-se que as ocupações infantis compreendem, principalmente, as áreas do brincar, escolar e do autocuidado (NELSON, 2004), e, nesse sentido, os contextos e ambientes que crianças com necessidades especiais vivenciam e que podem ser representados por pais, professores e profissionais da saúde/educação, cumprem função decisiva ao proporcionarem feedback positivo, melhorando a crença pessoal e incentivando estas crianças a se engajarem em novas atividades (GALVÃO; LAGE; RODRIGUES, 2008).

A família, enquanto contexto primário do desenvolvimento humano(CARTER; MCGOLDRICK, 2001), exerce um papel crucial na aquisição de conhecimento da criança sobre si mesma e sobre o ambiente externo (PASTORELLI et al., 2001). Ao 
proporcionarem experiências às suas crianças, familiares podem ser compreendidos como mediadores do processo de desenvolvimento infantil, o qual é resultanteda interação entre a criança engajada na atividade e seus ambientes (COPETTI; KREBS, 2004).

$\mathrm{Na}$ criança com necessidades especiais, a volição pode atuar como uma característica influente em potencial para o fazer significativo, facilitando o seu envolvimento em atividades do cotidiano, quando há vontade, ou restringindo a participação, quando não há vontade por parte da criança. Os atores envolvidos no cuidar desta criança se apresentam como importantes peças no processo volicional, e consequentemente, na promoção do desempenho ocupacional infantil.

Diante da relevância da influência que os contextos, ambientes e atores exercem no desempenho ocupacional infantil, e da escassez de investigações que abordam a temática das relações familiares e a volição de crianças com necessidades especiais, este estudo objetiva identificar como as mães percebem e lidam com a volição da criança com PC para realizarem atividades do cotidiano nas áreas escolar, do brincar e do autocuidado.

\section{Método}

A amostra foi selecionada por conveniência, a partir de uma série de familiares que acompanhavam seus filhos no serviço de reabilitação de uma unidade saúde-escola, em uma cidade de médio porte do interior do Estado de São Paulo e que preenchiam os critérios de inclusão: ser cuidador familiar principal de criança com PC, na faixa etária de 6 a 9 anos, inserida em escola regular e em tratamento de Terapia Ocupacional na unidade elegida.

Participaram seis mães de crianças com PC. As mães eram todas casadas, com idades entre 26 e 47 anos, escolaridade variando entre o ensino fundamental incompleto e médio completo, não trabalhavam fora de casa e permaneciam com a criança dois períodos do dia. Entre as crianças, três apresentavam nível motor I e três nível IV, segundo o Sistema de Classificação da Função Motora Grossa (GMFCS) (HIRATURA; MATSUKURA; PFEIFER, 2010), duas PC unilateral e quatro PC bilateral. O nível I do GMFCS indica maior independência e o nível IV, maior dependência nas atividades motoras. Três eram do sexo masculino e três do sexo feminino, e suas idades variaram de 6 a 9 anos. O Quadro 1 sintetiza os dados de caracterização das respectivas crianças. 
Quadro 1. Dados de caracterização das crianças com PC, filhos das mães participantes.

\begin{tabular}{|c|c|c|c|c|}
\hline Mãe & Sexo da criança & Idade da criança & $\begin{array}{c}\text { Tipo de PC da } \\
\text { criança }\end{array}$ & $\begin{array}{c}\text { Nível motor da } \\
\text { criança }\end{array}$ \\
\hline M1 & Masculino & 6 anos & Bilateral & IV \\
\hline M2 & Masculino & 8 anos & Unilateral & I \\
\hline M3 & Feminino & 8 anos & Bilateral & IV \\
\hline M4 & Feminino & 9 anos & Bilateral & IV \\
\hline M5 & Masculino & 9 anos & Bilateral & I \\
\hline M6 & Feminino & 6 anos & Unilateral & I \\
\hline
\end{tabular}

O estudo foi aprovado pelo Comitê de Ética em Pesquisa em Seres Humanos (parecer $\mathrm{n}^{\mathrm{O}}$ 121.155), e as participantes assinaram o Termo de Consentimento Livre e Esclarecido.

Para a coleta de dados, foram elaborados uma ficha de caracterização das participantes (contendo dados pessoais de identificação das mãese das crianças) e um roteiro de entrevista semiestruturada, com base no The Volitional Questionnaire (VQ) (HERAS et al., 2007). O VQ é uma escala desenvolvida a partir do MOH, voltada para crianças com idade acima de 6 anos, adolescentes e adultos, que não podem relatar sobre sua volição por apresentarem graves limitações funcionais. Apesar de ser um instrumento validado, em que as informações fornecem dados sobre os motivos internos e sobre como o ambiente afeta a volição da pessoa em ocupações, o VQ não foi utilizado por se tratar de uma escala observacional, não atendendo aos propósitos desse estudo, que busca investigar a partir da percepção das mães, aspectos da volição da criança com PC e do papel destes familiares no processo volicional infantil. Dessa forma, o instrumento criado foi baseado no $\mathrm{VQ}$, mas adaptado para ser dirigido às mães.

Um estudo preliminar foi conduzido por meio de duas aplicações-teste em uma população independente, a fim de refinar os instrumentos e aumentar a confiabilidade dos dados. Este estudo mostrou a necessidade de algumas adaptações no roteiro de entrevista. A versão derivada foi avaliada por dois juízes com experiência na área, que apreciaram a adequação das questões do roteiro aos objetivos do estudo e se a forma de perguntar estava adequada, como proposto por Manzini (2003). As sugestões foram contempladas na versão final do instrumento.

A coleta de dados foi realizada na unidade saúde-escola, em dia e horário agendado com cada mãe, que respondia a ficha de caracterização das participantes e a entrevista ${ }^{1}$ semiestruturada, audiogravada e, posteriormente, transcrita na íntegra.

Para análise dos dados, utilizou-se o procedimento de análise de conteúdo na modalidade temática (MORAES, 1999). Na primeira etapa da análise, foi realizada leitura detalhada e repetida das transcrições, apreendendo-se as ideias centrais. $\mathrm{Na}$ segunda etapa, leitura transversal de cada questão, para identificar os dados mais relevantes que constituíram os eixos temáticos. 
A fim de garantir o anonimato das participantes, estas foram identificadas pela letra M (mãe), seguida do número que reflete a sequência em que as entrevistas foram realizadas.

\section{Resultados e Discussão}

Apresentam-se, a seguir, os principais resultados e discussões, sistematizados de acordo com três eixos temáticos, que emergiram da análise das entrevistas.

\section{a) Percepção das mães sobre a volição das crianças}

Ao serem questionadas sobre quais atividades do cotidiano suas crianças demonstram ter maior volição em realizar, quatro das seis mães responderam ser as atividades de brincar e duas responderam ser as atividades escolares.

Para as mães, a volição de suas crianças é maior para atividades do brincar e escolares, uma vez que todas responderam que sua criança tem volição para realizar estes tipos de atividades, sendo que a volição é maior para as atividades escolares quando estas apresentam características lúdicas e de interação social, ou seja, quando se aproximam/assemelham às atividades do brincar. Nesse caso, depreende-se que a volição, para as mães, está associada ao interesse em realizar a atividade.

Para ele atividade escolar fica quase como um brincar com outras crianças. Ele gosta. É interesse pra brincar, né? De ir na areia e de ficar no parquinho. (Ml)

Ela gosta quando é aula de artes, ela se solta pra brincar, montam grupos, ela está no meio pra desenhar, não que ela saiba muito. (M3)

Tais falas permitem inferir que a dificuldade resultante da condição de PC em se movimentar e realizar a exploração dos objetos/ambiente, não impede que essas crianças tenham volição para o desempenho das atividades lúdicas. Pesquisas apontam que as dificuldades motoras e, por vezes cognitivas, não impedem crianças com PC de ter interesse e atitude para brincar (ZAGUINI et al., 2011; CAZEIRO, 2008; FERLAND, 2006). O estudo de Nunes et al. (2013), conduzido com crianças com desenvolvimento típico, mostra que: brincadeiras que fazem parte de seu comportamento ocupacional são, portanto, desejadas, ocupando boa parte de seu tempo no cotidiano. O estudo aqui conduzido aponta que, também para as crianças com PC, esta é a ocupação dominante em seu cotidiano que deve moldar comportamentos e habilidades no seu processo de desenvolvimento.

Assim, o ato de brincar, ao se configurar como principal ocupação da criança e permear todo o seu cotidiano (ZAGUINI et al., 20l1), faz com que o comportamento lúdico e o interesse para o brincar acompanhem o desempenho da criança também em outras áreas de ocupação, por exemplo, a escolar, como foi percebido no relato das mães. 
Por outro lado, as atividades escolares quando relativas às atividades acadêmicas formais da rotina do aluno na escola regular são apontadas como atividades que a criança tem pouca volição para realizar.

Eu acho que deve ser na hora que está ensinando. Porque ela (a professora) falou que na hora que ela vai dar a atividade para ele, senta com ele, começa a explicar e às vezes ele não quer fazer e joga fora. (Ml)

Ela gosta mais de pintar, recortar, não que ela tenha que ficar escrevendo muito... copiando as coisas. Ela não tem interesse de ficar num lugar sentada numa cadeira, quietinha, escutando o que a professora fala. (M6)

Esse resultado sugere que a questão da disciplina e das obrigações, como estudante, são vivenciadas por essas crianças apenas no contexto escolar, dificultando o desenvolvimento e a generalização da volição para as atividades acadêmicas formais, que, consequentemente, poderão comprometer o aprendizado e desempenho acadêmico desses alunos, uma vez que a volição é requisito fundamental para o fazer humano.

Nessa direção, é importante que os familiares percebam que suas crianças com PC têm condições de cumprir com obrigações, quando estas são coerentes às capacidades (motoras e cognitivas) da criança, e entendam a necessidade de estabelecer uma rotina para a criança em outros contextos que ela vivencia, como o domiciliar, estimulando os componentes do subsistema volicional: a causação pessoal, os valores e os interesses pessoais, descritos por Kielhofner (2009).

Ao considerar que estas crianças possuem níveis distintos de comprometimento motor, outra hipótese é que não apresentem volição para atividades acadêmicas formaispelas dificuldades em desempenhá-las (fruto de suas limitações físicas/ cognitivas). Somado a isso, deve-se atentar, também, para a falta de adaptação da escola, que precisa saber como lidar com as peculiaridades do aluno com necessidades educacionais especiais (NEE) para possibilitar o interesse, participação e envolvimento da criança nas atividades propostas dentro da classe regular, levando em consideração os princípios da educação inclusiva.

O fato de que o acesso à escola, em si, não garante que alunos com NEE tenham o devido suporte para o desenvolvimento do seu processo de ensino-aprendizagem faz necessária a atenção e reflexão continuada sobre a maneira como as escolas têm atuado com estas crianças. Na percepção das mães, a volição de seus filhos para realizar as atividades de autocuidado aparece em menor grau. Apenas duas mães relatam volição das crianças para este tipo de atividade, e uma relata que a volição depende da tarefa relativa ao cuidado pessoal da criança.

Demonstra (volição). Quando ele vai escovar o dente ele fala "mãe não consegui escovar direito, ajuda eu". Aí eu pego pra escovar também. (M2) 
Em algumas coisas (a criança tem volição). Ela não liga pra roupa, trocar. Mas ela gosta do banho, escovar o dente, na hora de comer, pegar as coisas sozinhas.(M3)

Sim (tem volição). Ela quer fazer sozinha. (M6)

Sobre essas atividades, nota-se que englobam várias tarefas, com maior nível de complexidade, ou seja, requerem mais habilidades por parte da criança, como a noção de sequenciamento e integração de componentes de desempenho sensóriomotores e cognitivos. Por um lado, esse dado pode estar relacionado à correlação frequentemente existente entre a gravidade do nível motor e o desempenho funcional, apresentado pelas crianças com PC (CHAGAS et al., 2008; MANCINI et al., 2004). Por outro lado, pode apontar que estas mães, por comumente realizarem as atividades de autocuidado pelas crianças, como tem sido demonstrado por alguns autores (OLIVEIRA; ALVES, 2011; OLIVEIRA; CORDANI, 2004), não apresentam muita medida da volição das crianças na rotina diária para realizarem este tipo de atividade.

É relevante destacar que, ao serem questionadas se consideram importante a criança ter volição para realizar as atividades cotidianas, de alguma forma as mães demonstraram que compreendem a relação volição versus envolvimento e participação da criança nas atividades, especificamente no autocuidado.

Este resultado é positivo e faz referência aos apontamentos do $\mathrm{MOH}$, ao entender que o desempenho ocupacional é influenciado pela volição, como um dos subsistemas que compreendem o ser humano (KIELHOFNER, 2009; HAGEDORN, 2003). Entretanto, considera-se preocupante apenas uma mãe ter demonstrado compreender a importância da interpretação das experiências pela criança e o subsequente reconhecimento de suas habilidades. Conforme Kielhofner (2009), a interpretação da experiência é uma das etapas fundamentais do ciclo de pensamentos e sentimentos de que consiste o subsistema da volição.

Considero importante, pra ela mesmo, a motivação dela fica... sente que ela pode fazer, quando ela vê que ela pode fazer é uma alegria e pra mim também é bom, cada vez mais ela vai... (M3)

\section{b) Percepção das mães sobre o seu papel no processo volicional das crianças}

Todas as mães consideraram muito importante a sua ajuda para a criança apresentar volição em realizar ou tentar participar das atividades do autocuidado, com diferentes justificativas.

Porque eu sou a pessoa que fica mais perto dele, que tem que incentivar ele. (Ml)

Porque a criança ela é só ensinada, né? E a gente que somos mãe, temos que ajudar a ensinar aquela rotina, né? (M2)

Porque é uma forma de estimular ela, porque se eu ficar quieta e não... ela fica pior ainda, ela vai achar que está bom do jeito que está. (M4) 
As mães reconhecem sua importância como principais mediadoras no processo de volição para realização de atividades do autocuidado, pelo vínculo, aproximação, tempo de permanência com a criança e também por uma questão de responsabilidade, por se sentirem na obrigação de ajudar e ensinar sua criança. Além disso, estas mães se percebem como uma referência para a criança, sinalizando o que está adequado/correto, o que pode ser considerado uma forma de estímulo à volição infantil. Esses achados são coerentes com os de Emmel (2009), que, em estudo sobre a influência do adulto no processo de desenvolvimento da criança, aponta o seu papel de mediador das relações entre a criança e os diversos universos sociais nos quais ela se insere, ajudando-a a constituir-se como um indivíduo social.

Sobre a ajuda para a criança apresentar volição para realizar as atividades do brincar, três mães responderam considerar sua ajuda como de importância mediana, duas muito importante e uma pouco importante.

Acho que é mediana, porque vontade de brincar é o que ela mais tem, já tem de sobra. (M6)

Muito importante, por isso também, né? De pegar na mão, colocar ela pra manusear um brinquedo, e ela vai começar com mais interesse, né? Brincar com uma coisa diferente que ela não tá acostumada. (M4)

Acho que é pouca (a importância), não preciso ajudar. (M5)

Para a volição nas atividades escolares, todas as mães responderam considerar muito importante a sua ajuda.

Muito importante por causa do incentivo, estar ali sempre com ela 'não, vamos fazer a lição, é importante você estudar', ter meu exemplo, né? Falar que eu sempre fui boa aluna, menina tem que ser boa aluna. (M3)

Muito importante. Pra incentivar ela a estudar, porque se eu deixar ela, ela não vai querer ir pra escola, ela não vai querer fazer trabalhinho de escola, então a gente tem que incentivar ela a fazer, né? As atividades da escola. Um pouco a gente tem que pegar no pé, porque senão ela vai largar. (M6)

Quando se trata do contexto escolar, nota-se que novamente estas mães se veem como importante fonte de apoio e incentivo para suas crianças terem volição e as justificativas são próximas às apresentadas para o autocuidado.

As diferenças aparecem para o brincar. Uma hipótese é que parte das mães acredita não precisar estimular a volição das crianças em brincar, porque esta atividade é própria da infância e não a valorizam como essencial para a promoção do desenvolvimento global do filho. Soma-se a isso, o fato de que a concepção dos familiares sobre o brincar, segundo Cruz e Emmel (2007), se refletirá nas atividades e oportunidades de brincar que a criança terá. 


\section{c) Estratégias utilizadas pelas mães para incentivar as crianças a desenvolverema volição}

Apesar de reconhecerem a importância de sua ajuda, quatro mães relataram não saber como incentivar sua criança a desenvolver a volição para atividades do autocuidado, revelando sentimentos de incerteza, insegurança e dúvidas.

Ainda não sei como eu tenho que fazer isso. Tá tão no automático tudo. (Ml)

Ah eu não sei, falando, né? 'Me ajuda', 'estica o bracinho pra mim'. (M4)

E agora? Nessa eu tô meio sem saber! (M5)

Não tenho ideia. Eu já pensei em tudo, não sei, essa eu não tenho ideia. (M6)

das.

As mães que dizem saber incentivar apontam algumas estratégias utiliza-

Principalmente à noite, ele vai escovar (os dentes), aí eu escovo também. (M2)

Estar ali junto mesmo, mostrando como seria legal ela fazer tudo sozinha, mais um incentivo mesmo. Mostrando 'olha como é legal você se esfregar sozinha', né? (M3)

Também foram notadas estratégias utilizadas pelas mães para incentivar sua criança a desenvolverem a volição para o brincar e para as atividades escolares.

Tudo que ela quer fazer sempre deixo ela fazer, ajudo ela, vou inventar uma brincadeira... sentar e brincar junto, ensinar como brinca. (M3)

Procurar brinquedos novos, outras coisas que possam interessar mais, alguma outra atividade, né? Ir mostrando, né? Estimulando mais um pouco. (M4)

Eu ajudo, eu sento com ela, faço a lição com ela, quer dizer incentivo, auxilio ela a fazer, não faço por ela. Mas é sentando e ajudando ela a fazer. (M6)

Observa-se que as mães auxiliam seus filhos a desenvolverem a volição para as atividades cotidianas ao se apresentarem como suporte para a criança e ao encorajá-las para a participação nas atividades que comumente não geram interesse. O suporte e encorajamento das pessoas próximas à criança, assim como mudanças na estrutura da atividade, são estratégias positivas e eficazes para aumentar o envolvimento do sujeito, possibilitando que o mesmo transite de um comportamento passivo para espontâneo (mostra comportamento sem suporte, estrutura ou encorajamento) frente à atividade (HERAS et al., 2007). 
Demais estratégias utilizadas pelas mães foram observadas, como conversar com a criança, orientar sobre a importância da atividade, tentar ensiná-la, supervisionar e fazer junto, como forma de incentivo para atividades que julgam importantes.

Merece reflexão o resultado das atitudes das mães com suas crianças, ao serem questionadas sobre como agem quando sua criança demonstra volição para atividades cotidianas e quando não demonstra. A maioria das mães utiliza estratégias opostas nas duas situações. Há uma tentativa de convencer e obrigar a criança a participar, quando esta não demonstra volição para o autocuidado e atividades escolares. Quando não há sucesso por parte da criança, admitem realizar a atividade de autocuidado pelo filho.

Eu tento ajudar ele. Se ele quer comer sozinho, eu ponho o pratinho lá e fico vendo ele comer sozinho. (Ml) (Quando a criança tem volição)

Incentivo, ajudo no que for preciso. Eu elogio. (M2) (Quando a criança tem volição)

Eu levo ele na escola. Mesmo não querendo. (Ml) (Quando a criança não tem volição)

Tem que puxar, tem que vestir, tem que calçar. Eu tenho que fazer por ela! Não tem outro jeito. (M3) (Quando a criança não tem volição)

Tais falas apontam que em alguns momentos os familiares de crianças com PC, não sabem como favorecer a vontade e a participação da criança em atividades, com atitudes que não incentivam a volição infantil. Nessa direção, ações de educação em saúde poderiam ser úteis, orientando cuidadores sobre características do processo volicional e componentes do subsistema volicional, ou seja, a importância de considerar a percepção da criança sobre sua capacidade e eficiência, seus valores e interesses, como também sobre a influência do contexto e do ambiente neste processo, como descrevem Kielhofner (2009), Heras et al. (2007) e Chern et al. (1996).

Características do processo volicional, dos componentes da volição e das influências contextuais, que devem ser consideradas por familiares e profissionais da educação e saúde, ao lidarem com crianças com necessidades especiais, são extraídas das entrevistas e apontadas a seguir, como a relevância da análise do ambiente social e físico, e das tarefas para a volição.

Acerca da influência do ambiente social, cinco mães relataram que seus filhos realizam a atividade que mais demonstra volição na companhia de outra(s) pessoa(s): familiares e/ou pares.

Gosta muito de brincar com o pai dele, com a vó, com o vô. (Ml)

Com os amiguinhos dele, com o priminho dele. (M2) 
Sobre os espaços em que as crianças realizam as atividades que mais demonstram volição, quatro mães relataram que frequentemente acontece no domicílio e duas relataram ser na escola. Elas revelaram características do motivo da escolha das crianças por estes ambientes.

Porque ali está tudo o que ela gosta, os brinquedos, o piano, a televisão com o DVD, ali tem tudo que ela gosta. (M4)

Ah ele gosta assim de ajudar a professora, a professora dá aqueles papel de fazer lição, aí ele vai entregando um pra cada coleguinha... acho que tem bastante criança, ele vê que a maioria é criança normal, né? Mas ele vê que ele é daquele jeito, então ele vê as outras crianças que não é, então acho que ele se sente que ele é independente, que ele consegue fazer as coisas ali... (M5)

Ter espaço e uma torneira que ela consegue abrir pra pegar água. (M6)

Assim, o ambiente físico de interesse da criança se configura como um espaço familiar, rotineiro, de tamanho apropriado para permitir executar o que deseja, com objetos atrativos ao alcance, possibilidade de realização das atividades e consequente percepção de competência, o que faz a criança se sentir bem. $\mathrm{O}$ ambiente social é outro que ajuda a definir a participação da criança. A companhia de pessoas com quem se sente confiante e/ou que podem servir como parceiros em uma atividade parece ajudar no processo de volição, até porque, na faixa etária dessas crianças, período de transição do estágio pré-operacional para o das operações concretas, segundo a Teoria do Desenvolvimento de Piaget (FARIA, 1993), o processo de aprendizagem é mediado, principalmente, pela imitação, jogos simbólicos e jogos de regras, sendo fundamental a presença de outras crianças, seus pares. Emmel (2009) afirma que a interação com o outro (seja adulto ou criança mais experiente) pode ser muito positiva nesse processo, uma vez que traz para a criança novas bases para novas aprendizagens.

Sobre a escolha das tarefas ocupacionais, cinco mães relataram que, geralmente, são os próprios filhos que escolhem a atividade que mais demonstram volição em realizar. Desta maneira, a criança escolhe aquilo que se julga capaz de fazer, que é significativo para ela, que lhe proporciona prazer e bem estar, ou seja, utiliza de todos os componentes do subsistema volicional para orientar sua seleção de atividades e a depender das exigências do ambiente, o desempenho ocupacional será estimulado ou impedido (REBELLATO, 2012; KIELHOFNER, 2009; POLIA; CASTRO, 2007).

\section{Conclusão}

Em geral, as mães participantes do estudo percebem a relação volição da criança versus participação e envolvimento nas atividades cotidianas, assim como a importância delas no processo volicional infantil, inclusive realizando algumas estratégias de incentivo para auxiliar as crianças a desenvolverem a volição para atividades que julgam relevantes, principalmente, as escolares formais e as do autocuidado, com menor consideração para as do brincar. 
No entanto, o conhecimento das mães sobre as estratégias de incentivo para a criança desenvolver a volição é limitado, gerando dificuldades e certa angústia para lidar com situações em que não há volição e que as mães consideram importantes para a vida de seus filhos.

Considera-se necessário um direcionamento das ações de educação em saúde para a orientação dos familiares de crianças com necessidades especiais, como as com PC, no sentido de ampliar o repertório de estratégias destes mediadores do desenvolvimento infantil, a partir do entendimento dos aspectos que influenciam o subsistema volicional.

Apesar da limitação da amostra, no que se refere ao número de participantes e diferenças nas características das crianças, essa investigação atingiu os objetivos propostos e aponta novas questões a serem exploradas em estudos futuros.

Acredita-se ter acrescentado ao conhecimento produzido na área da Educação Especial, acerca da reflexão sobre fatores de risco e proteção ao desenvolvimento humano, direcionando estratégias de educação e saúde que considerem amplamente o contexto familiar, que gerem um ambiente favorável à promoção do desempenho ocupacional nas crianças com necessidades especiais e forneçam atenção à criança com PC, ao considerar seu processo volicional para realizar atividades do cotidiano, por meio da compreensão da volição como um importante requisito para o fazer humano.

\section{Referências}

CARTER, B.; MCGOLDRICK, M. As mudanças no ciclo de vida familiar: uma estrutura para a terapia familiar. 2. ed. Porto Alegre: Artes Médicas, 2001.

CASTANHARO, R. C. T. A percepção de adolescentes gestantes acerca dos papéis ocupacionais e do futuro papel materno. 2011. 117 f. Dissertação(Mestrado em Enfermagem) - Setor de Ciências da Saúde, Universidade Federal do Paraná, Curitiba, 2011.

CAZEIRO, A. P. M. Formação de conceitos por crianças com paralisia cerebral: um estudo exploratório sobre as influências das brincadeiras. 2008. 301 f. Dissertação (Mestrado em Psicologia Escolar) - Instituto de Psicologia, Universidade de São Paulo, São Paulo, 2008.

CHAGAS, P. S. C. et al. Classificação da função motora e do desempenho funcional de crianças com paralisia cerebral. Revista Brasileira de Fisioterapia, v. 12, n. 5, p. 409-416, set./out. 2008.

CHERN, J. et al. The volitional questionnaire: psychometric development and practical use. American Journal of Occupational Therapy, v. 50, p. 516-525, 1996.

COPETTI, F.; KREBS, R. J. As propriedades da pessoa na perspectiva do paradigma ecológico. In: KOLLER, S. H. Ecologia do desenvolvimento humano: pesquisa e intervenção no Brasil. São Paulo: Casa do Psicólogo, 2004. p. 67-89.

CRUZ, D. M. C.; EMMEL, M. L. G. O Brinquedo e o brincar na estimulação da função manual de crianças pré-escolares com deficiência física. Cadernos de Terapia Ocupacional da UFSCar, v. 15, n. 1, 2007.

Revista Educação Especial | v. 27 | n. 48 | p. 185-200 | jan./abr. 2014

Santa Maria 
EMMEL, M. L. G. Proposições sobre o significado e a função do brincar no desenvolvimento infantil. IN: MENDES, E.G.; ALMEIDA, M.A.; WILLIAMS, L.C.A. Temas em educação especial: avanços recentes. São Carlos: EDUFSCar; 2009. p. 85-90.

FARIA, A. R. Desenvolvimento da criança e do adolescente segundo Piaget. 2. ed. São Paulo: Ática, 1993.

FERLAND, F. O modelo lúdico: o brincar, a criança com deficiência física e a terapia ocupacional. 3. ed. São Paulo: Roca, 2006.

GALVÃO, B. A. P.; LAGE, N. V.; RODRIGUES, A. A. C. Transtorno do desenvolvimento da coordenação e senso de auto-eficácia: implicações para a prática da terapia ocupacional. Revista de Terapia Ocupacional da Universidade de São Paulo, v. 19, n. 1, p. 12-19, 2008.

HAGEDORN, R. Fundamentos para a prática em terapia ocupacional. 3. ed. São Paulo: Roca, 2003.

HERAS, C. G. et al. The volitional questionnaire (VQ). Version 4.1. Chicago: Department of Occupational Therapy, University of Illinois at Chicago, 2007.

HIRATURA, E.; MATSUKURA, T. S.; PFEIFER, L. I. Adaptação transcultural para o Brasil do sistema de classificação da função motora grossa (GMFCS). Revista Brasileira de Fisioterapia, v. 14, n. 6, p. 537-544, nov./dez. 2010.

KIELHOFNER, G. Model of human occupation: theory and application. 3. ed. Baltimore: Lippincott Williams \& Wilkins, 2002.

The model of human occupation. In: KEILHOFNER, G. (Org.). Conceptual foundations of occupational therapy practice. 4. ed. Philadelphia: F. A. Davis Company, 2009, p. 150-174.

LAMMI, B. M.; LAW, M.The effects of family-centredfunctional therapy on the occupational performance of children with cerebral palsy.Canadian Journal of Occupational Therapy, v. 70, n. 5, p. 285-296, 2003.

LEITE, J.M.R.S.; PRADO, G. F. Paralisia cerebral: aspectos fisioterapêuticos e clínicos. Revista Neurociências, v. 12, n. 1, p. 41-45, 2004.

MANCINI, C. M. et al. Gravidade da paralisia cerebral e desempenho funcional. Revista Brasileira de Fisioterapia, v. 8, n. 3, p. 253-260, 2004.

MANZINI, E. J. Considerações sobre a elaboração de roteiro para entrevista semiestruturada. In: MARQUEZINE, M. C.; ALMEIDA, M. A.; OMOTE, S. (Orgs). Colóquios sobre pesquisa em educação especial. Londrina: Eduel, 2003. p. 11-25.

MORAES, R. Análise de conteúdo. Revista Educação, v. 22, n. 37, p. 7-32, 1999.

NELSON, C. A. Paralisia cerebral. In: UMPHRED, D. A. Reabilitação neurológica. 4. ed. Barueri: Manole, 2004, p. 272-299.

NUNES, F.B.S.et al. Retratos do cotidiano de meninos de cinco e seis anos: a atividade de brincar. Cadernos de Terapia Ocupacional da UFSCar, v. 21, n. 2, p. 1-13, 2013.

OLIVEIRA, A. K. C.; ALVES, A. C. J. Atividades de autocuidado em crianças com paralisia cerebral e a percepção dos cuidadores. Temas sobre Desenvolvimento, v. 18, n. 103, p. 149-153, 2011.

OLIVEIRA, M. C.; CORDANI, L.K. Correlação entre habilidades funcionais referidas pelo cuidador e nível de assistência fornecida a criança com paralisia cerebral. Arquivos Brasileiros de Paralisia Cerebral, v. 1, n. 1, p. 24-29, set./dez. 2004. 
PASTORELLI, C. et al. The structure of children's perceived self-efficacy: a cross-national study. European Journal Psychologic Assessment, v. 17, n. 2, p. 87-97, 2001.

POLIA, A. A; CASTRO, D. H. A lesão medular e suas sequelas de acordo com o modelo de ocupação humana. Cadernos de Terapia Ocupacional da UFSCar, v. 15, n. 1, p. 19-29, jan.jun. 2007.

REBELLATO, C. Relações entre papéis ocupacionais e qualidade de vida em idosos da comunidade. 2012. 241 f. Dissertação (Mestrado em Terapia Ocupacional) - Centro de Ciências da Saúde,Universidade Federal de São Carlos,São Carlos, 2012.

ROSEMBAUM, P. et al. A report: the definition and classification of cerebral palsy abril2006. Developmental Medicine and Child Neurology, v. 49, supl. 109, p. 8-14, 2007.

ZAGUINI, C. G. S. et al. Avaliação do comportamento lúdico da criança com paralisia cerebral e da percepção de seus cuidadores. Acta Fisiátrica, v. 18, n. 4, p. 187-191, 2011.

\section{Correspondência}

Alyne Kalyane Câmara de Oliveira - Universidade Federal de São Carlos, Centro de Educação e Ciências Humanas, Departamento de Educação Especial. Rodovia Washington Luiz, Km 235, CEP: 13565-305, São Carlos, São Paulo, Brasil.

E-mail: alynekoliveira@hotmail.com - malu@ufscar.br

Recebido em 01 de julho de 2013

Aprovado em 04 de outubro de 2013 
